\title{
Trauma-Informed Social Work Practice with Women with Disabilities: Working with Survivors of Intimate Partner Violence
}

\author{
Michelle S. Ballan \\ Molly Freyer
}

\begin{abstract}
Women with disabilities experience intimate partner violence (IPV) at higher rates than both nondisabled women and men, and men with disabilities. Their significant exposure to IPV suggests notable levels of trauma-related symptomology. However, there is a dearth of research on trauma and IPV among women with disabilities, and services tailored to their diverse strengths and needs are scarce. Guided by critical disability theory and feminist disability theory, this article describes culturally sensitive, trauma-informed approaches to practice with female survivors of IPV with disabilities.
\end{abstract}

Keywords: Intimate partner violence; women with disabilities; trauma-informed practice

Women with disabilities are among the most vulnerable groups impacted by intimate partner violence (IPV), which includes physical, sexual, psychological, and economic abuse. They experience IPV at higher rates than nondisabled women and men, and men with disabilities (Breiding \& Armour, 2015) and are more often subject to severe forms of physical abuse, including being kicked, punched, or bitten (Brownridge, 2006). Women with disabilities also experience subtle forms of abuse exploiting aspects of disability, such as withholding medication or denying needed supports (Lund, 2011). The most common perpetrators of violence against women with disabilities are former or current intimate partners (Hahn, McCormick, Silverman, Robinson, \& Koenen, 2014), but family members, caregivers, personal assistants, and medical providers may also be perpetrators (Curry et al., 2009). The experience of abuse is compounded as women with disabilities remain in abusive relationships for longer periods of time than nondisabled women (Nosek, Howland, Rintala, Young, \& Chanpong, 2001).

The impact of trauma on women with disabilities is under-researched, and its origins misunderstood. One study comparing trauma symptomatology among men and women both with and without disabilities found that women with disabilities reported significantly higher levels of trauma symptoms compared to men with disabilities and nondisabled men and women (Strauser, Lustig, \& Uruk, 2007). Traumatic experiences can compound health problems among women with disabilities, as trauma has been linked with physical health problems, as well as poor health behaviors such as substance abuse (Weissbecker \& Clark, 2007).

Despite the problem's gravity, there is a dearth of research on trauma and IPV among women with disabilities, and services tailored to their diverse needs are scarce. Research on trauma-informed practice with this population is particularly limited (Anderson \& Najavits, 2014). Trauma-informed practice is emerging as an effective approach to addressing the needs of female survivors experiencing IPV and related traumatic life experiences (Taft, Murphy, \& Creech, 2016). However, a systematic review of the

Michelle S. Ballan, PhD, is Professor of Social Welfare and Professor of Family, Population and Preventive Medicine,

Stony Brook University, Health Sciences Center, 101 Nicolls Road, Stony Brook, NY, 11794. Molly Freyer, LCSW, is a

doctoral student at NYU Silver School of Social Work, 1 Washington Square N, New York, NY 10003 
empirical research found not a single effective IPV intervention for women with disabilities (Mikton, Maguire, \& Shakespeare, 2014), and the utility of trauma-informed practice has yet to be explored with this population. In this article, we consider culturally sensitive, trauma-informed approaches to practice for female survivors of IPV with disabilities.

\section{Background: IPV, Disability, and Trauma-Informed Practice}

Empirical research confirms that women with disabilities are disproportionately affected by IPV. According to the 2013 National Crime Victimization Survey, individuals with disabilities experienced serious violent victimization at three times the rate of those without disabilities, and were more likely to experience serious violent victimization by an intimate partner (Harrell, 2015). The 2010 National Intimate Partner Violence and Sexual Violence Survey revealed that women with a disability were significantly more likely to experience sexual and physical violence, stalking, psychological aggression, and control of reproductive or sexual health than women without a disability (Breiding \& Armour, 2015).

Compounding the risks faced by victims with disabilities, IPV is associated with longterm physical and mental health problems. The health-related risks of IPV are of particular concern. The World Health Organization (2011) cites violence against women with disabilities as a major factor in their diminished health status, linking violence to "immediate and long-term" health outcomes including "injuries, physical and mental health problems, substance abuse, and death" (p. 59). IPV is associated with a wide range of mental health issues, including depression, post-traumatic stress disorder (PTSD), anxiety, self-harm, and sleep disorders (Dillon, Hussain, Loxton, \& Rahman, 2013). Furthermore, IPV is more common among women with serious or chronic mental illness, and studies have shown that women with chronic mental illness are more likely to attempt suicide as a result of IPV, and less likely to seek help from informal networks of support (Khalifeh, Oram, Trevillion, Johnson, \& Howard, 2015).

Women with disabilities also face unique risk factors for abuse, including physical and social isolation; difficulty identifying abuse; dependence on abusive partners for assistance with daily needs; and general vulnerability related to disability, such as physical difficulty escaping abusive environments (Plummer \& Findley, 2012). Social messages regarding the asexuality and undesirability of women with disabilities as intimate partners denigrates self-esteem, which is associated with IPV (Hassouneh-Philips \& McNeff, 2005). Poverty and unemployment further reduce alternatives to abusive relationships for women with disabilities (Nosek et al., 2001), who are also impacted by structural inequalities related to race, gender, socioeconomic status, sexual orientation, and age (Ortoleva \& Lewis, 2012).

The need for evidence-based interventions is frequently noted in the literature, with a particular need to develop approaches tailored to women with physical, sensory, and/or psychiatric disabilities (Lund, 2011; Mikton et al., 2014). Typical IPV violence intervention efforts for women with disabilities have been to modify approaches used with nondisabled women informed by traditional domestic violence theory (Barranti \& Yuen, 2008). Applying the same intervention tactics assumes that the causes and consequences 
of IPV are similar for nondisabled women and women with disabilities, when research has shown they often are not (Plummer \& Findlay, 2012).

Women with disabilities may face great difficulty accessing support services, such as IPV agencies or the police, due to isolation, physical and attitudinal barriers among service agencies and providers, and fear of retribution by the abuser (Chang et al., 2003). If women with disabilities do seek assistance from IPV agencies, they may find that these agencies, and those working within them, are inadequately prepared to meet the needs of survivors with disabilities. The physical and attitudinal inaccessibility of these agencies has been cited as a barrier to escaping an abusive relationship (Chang et al., 2003; Frantz, Carey, \& Nelson-Bryen, 2006). Furthermore, the barriers preventing women with disabilities from accessing support, such as isolation, inaccessibility, and a lack of empowerment, may be exacerbated by trauma-related conditions such as PTSD (Anderson \& Najavits, 2014).

Abuse among women with disabilities has largely been addressed within either domestic violence organizations lacking experience with this population, or disabilityfocused organizations unfamiliar with IPV. In a National Census of Domestic Violence Services, the National Network to End Domestic Violence (2016) found that seventy-two percent of agencies surveyed reported providing advocacy related to disability issues throughout the year. It is critical that these agencies have the necessary tools to provide culturally relevant services to assist women with disabilities in their efforts to cope, heal, and achieve safety from abuse. Accessibility moves beyond physical infrastructure and considers the needs of women with disabilities in their policies and practices, establishing relationships with disability organizations and interpreter services, and accommodating women with varying levels of medication use, service animals, and personal care attendants. These accessibility considerations extend to trauma-informed practice with survivors of IPV with disabilities.

\section{Trauma-Informed Practice}

Trauma-informed IPV practice is driven by an understanding of the impact of violence and trauma, past and present, on all aspects of an individual's life and development (Elliott, Bjelajac, Fallot, Markoff, \& Reed, 2005). In a trauma-informed system, trauma is viewed not as a single discrete event but rather as a defining and organizing experience that forms the core of an individual's identity (Harris \& Fallot, 2001). Systems of care operating from a trauma-informed approach design, organize, and implement all aspects of the clinical encounter to reflect an understanding of how trauma affects the life of the individual seeking services (Ghandour, Campbell, \& Lloyd, 2015). The core values of safety, trustworthiness, choice, collaboration, and empowerment are defining features of service settings utilizing a trauma-informed approach (Fallot \& Harris, 2009). This includes ensuring that all staff working within the setting are trained on trauma-relevant information and skills, and have the competencies to work with a range of individuals and experiences (Ghandour et al., 2015).

Trauma-informed IPV practice with women with disabilities requires an understanding of the complex interplay of medical, social, political, and personal factors influencing the experience of trauma within this population. Quiros and Berger (2015) note that an agency 
that is truly trauma-informed must align itself with the social work mission of social justice, considering structural and environmental conditions when assessing trauma; that is, trauma is experienced on both interpersonal and sociopolitical levels. A comprehensive, traumainformed response to IPV for women with disabilities must begin by addressing the full constellation of disability-related risk factors and consequences of abuse, at both personal and structural levels.

\section{Lessons from Past Research}

In addition to the tenets of trauma-informed practice discussed above, our past research suggests areas of focus for survivors of IPV with disabilities. Our preliminary research (Ballan et al., 2014; Ballan, Burke Freyer, \& Powledge, 2015; Ballan, Burke Freyer, Powledge, \& Marti, 2016) examined familial, social, and contextual correlates of IPV among individuals with disabilities and barriers to self-protection. This research yielded insight into the factors motivating women with disabilities to seek assistance and the need to increase women's independence and self-efficacy to enable them to find alternatives to violent relationships.

Health-related factors such as dependence on abusers for assistance with activities of daily living, social factors such as reduced community inclusion and lack of employment options, and personal factors such as the desire to retain custody of one's children all present significant barriers to addressing IPV. Findings indicated that female IPV victims with disabilities were often married and/or had children, challenging previous research and stereotypical portrayals of women with disabilities as single and childless. The possibility of losing custody of one's children is a great deterrent to reporting abuse among women with disabilities, as perpetrators may erroneously claim that disability negatively impacts parenting ability (Ortoleva \& Lewis, 2012). Elliott et al. (2005) suggest including traumainformed parenting services for survivors of trauma with children, helping parents explore how to take care of their own feelings, as well as those of their children.

The exclusion of women with disabilities from education and employment is a structural issue which has serious individual consequences. High rates of unemployment within our study sample indicated the need for vocational and financial assistance as standard components of IPV interventions. Moreover, it guides practitioners to consider additional needs such as permanent housing and accessible affordable healthcare accompanying unemployment and low socioeconomic status. Women with disabilities are disproportionately poor when compared to the general population (Hassouneh-Philips, McNeff, Powers, \& Curry, 2005), which is by large a result of their secondary social status, and creates further difficulty in attempting to gain independence from an abuser. Economic independence has a great impact on a woman's ability to escape an abusive relationship, and stable employment is one crucial means of attaining financial stability. Social workers need to be apprised of services such as vocational training and benefits such as Supplemental Security Income (SSI) and Social Security Disability Insurance (SSDI), and understand the distinction between the various entitlements available to women with disabilities. An important role will be to serve as a link between the survivor and these federal and state resources. 
Our previous research likewise indicated that practitioners must consider how needs may vary based on disability type. Literature on violence and women with disabilities has included a range of disabilities in the study sample, yet generally fails to examine abuse among specific disability groups (Hughes et al., 2011). It is essential for intervention methods to account for the interplay of disability, abuse, and related psychosocial dimensions, and acknowledge how these factors impact the health, well-being, and options of women with disabilities (Copel, 2006). A critical consideration entails assessing disability status and how this interacts with the effectiveness of interventions for IPV survivors.

Below, we discuss theoretical approaches related to IPV and disability, and provide recommendations for integrating these into trauma-informed practice with survivors with disabilities.

\section{Recommendations for Trauma-Informed Practice with Survivors of IPV with Disabilities}

The unique range of factors influencing the experience of IPV among women with disabilities requires a consideration of disability-informed theoretical approaches to the problem. Concepts drawn from critical disability theory and feminist disability theory provide a thorough foundation for culturally sensitive, trauma-informed practice with survivors with disabilities. Traditional trauma theory neglects to consider the diversity of experiences shaped by race, ethnicity, and disability status, among other identities (Quiros $\&$ Berger, 2015). The tenets of critical disability theory and feminist disability theory remind practitioners of the salience of intersecting identity statuses to each individual's experience of trauma.

Critical disability theory (Shakespeare, 2014) views disability as an interaction between individual, or intrinsic factors, and structural/contextual factors. The intrinsic factors include issues such as the type and severity of one's impairment, one's own feelings about the impairment, and additional personality and psychological characteristics. Contextual factors include the attitudes and reactions of others to one's impairment, the extent to which one's immediate environment is accommodating of disability, and wider cultural, social, and economic issues relevant to disability. Critical disability theory reminds practitioners that women with disabilities cannot be treated as a homogeneous group, as personal experience will vary based on disability type. The severity of one's impairment influences her ability to respond to IPV on a personal level. The system of social networks, agencies, and institutions surrounding survivors of abuse with disabilities, and their ability and willingness to support them, profoundly impacts a woman's options. Finally, the broader influence of general social and cultural attitudes toward disability shapes the experience of perceived vulnerability to abuse, discrimination and lack of responsiveness to women with disabilities experiencing IPV.

Feminist disability theory (Asch \& Fine, 1988; Garland-Thompson, 2002) draws attention to the intersecting statuses of gender and disability, viewing violence against women with disabilities through the lens of disability- and gender-based oppression. These attitudes manifest at the social and political level, but filter down to the personal level. 
Intersectional concepts further shed light on this phenomenon, but stress a consideration of intersecting statuses beyond gender and disability, such as race, ethnicity, immigration status, sexual orientation, age, and socioeconomic status.

Focusing solely on individual factors when constructing interventions for survivors of IPV with disabilities ignores broader structural factors contributing to the problem, and contributes to victim-blaming and marginalization (Mays, 2006). Barranti and Yuen (2008) likewise argue that traditional models of IPV prevention and intervention do not consider the reality of social oppression. They suggest that feminist disability theory can correct for the current inadequacies inherent in IPV services for women with disabilities by "emphasizing issues of gender, disablism, poverty, and the inherent social oppression that intersect in the experience of IPV and abuse of women with disabilities" (p. 128). Traumainformed practice with survivors with disabilities should begin with a consideration of these issues and how they impact the healing process.

The tenets of the theoretical frameworks described above, along with the core traumainformed values (Fallot \& Harris, 2009) can inform practice with survivors with disabilities. More specifically, the Substance Abuse and Mental Health Services Administration (SAMHSA; 2015) direct trauma-informed intervention programs recognize the following:

The survivor's need to be respected, informed, connected, and hopeful regarding their own recovery; The interrelation between trauma and symptoms of trauma such as substance abuse, eating disorders, depression, and anxiety; The need to work in a collaborative way with survivors, family and friends of the survivor, and other human services agencies in a manner that will empower survivors and consumers (para. 3).

Using these specific guidelines, we consider how to integrate trauma-informed practice's core values, along with the issues raised by critical disability theory and feminist disability theory, to guide social workers in providing culturally sensitive, trauma-informed practice with IPV survivors with disabilities. See Table 1 for a summary of our recommendations.

\section{The Survivor's Need to be Respected, Informed, Connected, and Hopeful}

Respect begins with seeking to understand what the survivor wants when accessing assistance. When a woman with a disability seeks IPV related assistance, the goal may not always be to leave the abusive relationship, understanding that some women will be reluctant if the perpetrator is someone on whom she depends for assistance with daily needs (Martin et al., 2006). Women with disabilities also face the loss of accessible housing, barriers in the criminal justice system, and threats to their independence if they report abuse, among a host of concerns (Ortoleva \& Lewis, 2012).

Social workers serving survivors of IPV with disabilities must guard against making assumptions based on disability, and not allow the disability to overshadow other relevant aspects of the woman's experience. Disability may present personal challenges on an individual level, but the social oppression stemming from disability-based discrimination, both visible and invisible, is equally damaging. Focusing narrowly on the individual 
experience of disability neglects the diverse psychosocial context of one's life; it also neglects the social context of disability. Yet social workers may fail to see beyond a woman's disability, and assume that the disability itself is the presenting problem. For instance, women with disabilities who seek help from IPV agencies are often diverted to disability service agencies because providers perceive their disability, rather than the abuse, as the primary treatment need (Cramer, Gilson, \& DePoy, 2003). This invalidates the woman's experience of IPV and dilutes the effectiveness of the response. As a social worker, one can raise all relevant issues and safety concerns, but ultimately the goals of intervention must be defined on the survivor's own terms, in her own words.

Survivors with disabilities will feel respected, informed, connected, and hopeful if social workers express an understanding of disability-related needs and considerations when responding to IPV. For instance, safety planning, a common aspect of IPV interventions, can be modified to address disability-related needs in collaboration with the survivor. Creating a safety plan in collaboration with women with disabilities puts the survivor in control and teaches skills which can be individually executed, as opposed to a social worker assuming full responsibility and control. Hoog (2004) provides the following guidelines in constructing an empowering safety plan:

The advocate should ask the survivor about the physical and attitudinal barriers that are affecting her safety. The survivor with a disability is the expert on what safety techniques will work best for them... When developing safety planning strategies, the advocate should ask about and incorporate the practical ways a person with a disability navigates barriers. Advocates should consider using support services that the survivor wants to use in the safety planning process. (p. 8-9)

Recognizing the survivor's strengths employed in coping with the abuse up until the point of intervention is paramount.

\section{The Interrelation Between Trauma and Symptoms of Trauma}

Substance abuse, eating disorders, depression, and anxiety are noted mental health concerns related to trauma (SAMHSA, 2015). Psychiatric disabilities have been found to precede IPV, serving as a potential risk factor, as well as occurring as a result of IPV (Devries et al., 2013). Social workers working with survivors of trauma must be vigilant to the possibility that unresolved mental health issues could increase one's vulnerability to IPV, while also screening for mental health issues resulting from trauma.

A previous study of female IPV survivors with disabilities determined that almost $72 \%$ of the study sample was diagnosed with a psychiatric disability of some type, and the majority of women with physical disabilities also had a psychiatric disability (Ballan et al., 2014). However, less than half of all safe homes, shelters, and transitional housing services in the U.S. provide mental health services to survivors of IPV (Douglas \& Hines, 2011). Agencies addressing IPV, particularly those serving women with disabilities, must offer comprehensive mental health services. This unmet need warrants immediate attention. Untreated mental illness further compromises a woman's ability to respond effectively to abuse and other unsafe situations (Hoog, 2004). 


\section{The Need to Work Collaboratively}

Collaboration in treatment, which includes providing choices and empowering survivors to make their own choices regarding their personal safety, is essential to traumainformed practice with survivors with disabilities. This point is especially salient, as issues of power and control are paramount in practice with survivors of IPV. Social workers should strive to restore a sense of power to the survivor, and this may begin simply by asking her how she would like to proceed. Ensure that the survivor is defining her own goals, related to both disability and IPV.

Reaching consensus regarding the goals of intervention requires an equal collaboration between social workers and survivors. Women with disabilities should be in control of the forms of assistance they choose to utilize, and be assured appropriate resources in order to access what is needed. Women with disabilities have reported feeling invalidated, discounted, and objectified in healthcare settings, noting a sense that providers take over their care (Hassouneh-Phillips et al., 2005). The services provided to survivors should be chosen by the woman with the disability herself, to the extent possible. For example, knowledge about one's options in hiring, securing, and firing personal care assistants is an abuse prevention tool which acknowledges the medical need for care while allowing the woman with a disability to take control of this assistance.

In addition to collaborating with the survivor, it is essential to work collaboratively with other agencies within the community to address the survivor's needs. Arranging meetings between IPV- and disability-focused agencies, as well as healthcare providers and representatives from the criminal justice system, aids in the sharing of information and building of rapport. The social worker can serve as an advocate in this process, assisting the IPV survivor to access the trauma-related assistance she desires.

Table 1. Recommendations for Trauma-Informed Practice with Survivors of IPV with Disabilities

\begin{tabular}{|l|l|}
\hline $\begin{array}{l}\text { Trauma-Informed } \\
\text { Principle }\end{array}$ & Recommendations \\
\hline $\begin{array}{l}\text { Considerations from } \\
\text { critical disability } \\
\text { theory and feminist } \\
\text { disability theory }\end{array}$ & $\begin{array}{l}\text {-Avoid treating women with disabilities as a homogeneous group } \\
\text {-Consider personal factors such as type and severity of impairment, } \\
\text { and one's adaptations to it; contextual factors such as the extent to } \\
\text { which one's immediate environment is accommodating of disability; } \\
\text { as well as wider cultural, social, and economic issues related to } \\
\text { disability } \\
\text {-Attend to the personal, social, and political contexts of gender and } \\
\text { disability, as well as race, ethnicity, immigration status, sexual } \\
\text { orientation, age, and socioeconomic status }\end{array}$ \\
\hline $\begin{array}{l}\text { The survivor's need to } \\
\text { be respected, } \\
\text { informed, connected, } \\
\text { and hopeful }\end{array}$ & $\begin{array}{l}\text {-Define goals of intervention in the survivor's own terms, in her own } \\
\text { words } \\
\text {-Express an understanding of disability-related needs and } \\
\text { considerations when responding to IPV } \\
\text {-Recognize the survivor's strengths }\end{array}$ \\
\hline
\end{tabular}




\begin{tabular}{|l|l|}
\hline $\begin{array}{l}\text { Interrelation between } \\
\text { trauma and symptoms } \\
\text { of trauma }\end{array}$ & $\begin{array}{l}\text {-Screen for mental health issues associated with trauma } \\
\text {-Recognize that unresolved mental health issues can increase } \\
\text { vulnerability to IPV } \\
\text {-Provide mental health services/address mental health in IPV agencies }\end{array}$ \\
\hline $\begin{array}{l}\text { The need to work } \\
\text { collaboratively }\end{array}$ & $\begin{array}{l}\text {-Provide choices and empower survivors to make their own choices } \\
\text { regarding personal safety } \\
\text {-Ensure that the survivor is defining her own goals related to both } \\
\text { disability and IPV } \\
\text {-Give control to the survivor in the forms of disability assistance one } \\
\text { chooses to utilize } \\
\text {-Work collaboratively with agencies in the community to address the } \\
\text { survivor's needs }\end{array}$ \\
\hline
\end{tabular}

Conclusion

Women with disabilities are disproportionately affected by IPV, yet disabilitysensitive, trauma-informed practice is in its infancy. In order to make trauma-informed practice truly accessible to survivors of IPV with disabilities, the effectiveness of evidencebased trauma-specific interventions must be researched with this population. Promising research on trauma-informed interventions such as Seeking Safety has revealed its effectiveness with women with physical disabilities; however, the study's authors acknowledge the need for more research with a larger, more diverse sample of women with disabilities (Anderson \& Najavits, 2014). Diversity is notably lacking in previous studies of IPV among women with disabilities (Hughes et al., 2011), which tend to represent mainly white, college-educated women. Prior research by this team (Ballan et al., 2014) indicates that women with disabilities who seek IPV services are substantially more diverse than those sampled in abuse and disability research, and underscores the need to examine distinct groups of women with disabilities. Women with disabilities form a diverse population with varying experiences, needs, strengths, and expertise. Trauma-informed practice with survivors must respect this diversity, while understanding the unique ways in which disability impacts the experience of abuse. Social workers will need to be vigilant to ensure equality of access, not simply in disability terms, but also in respect to aspects of identity such as race, ethnicity, sexual orientation, and immigration status. Approaching trauma-informed practice from the theoretical foundation of critical disability theory and feminist disability theory ensures that these considerations are kept central to culturally sensitive IPV interventions with women with disabilities.

\section{References}

Americans with Disabilities Act (ADA) P.L. 101-336 (1990).

Anderson, M. L., \& Najavits, L. M. (2014). Does seeking safety reduce PTSD symptoms in women receiving physical disability compensation? Rehabilitation Psychology, 59(3), 349-353. doi: https://doi.org/10.1037/a0036869

Asch, A., \& Fine, M. (1988). Introduction: Beyond pedestals. In A. Asch \& M. Fine (Eds.), Women with disabilities: Essays in psychology, culture, and politics (pp. 132). Philadelphia, PA: Temple University Press. 
Ballan, M. S., Burke Freyer, M., Marti, C. N., Perkel, J., Webb, K. A., \& Romanelli, M. (2014). Looking beyond prevalence: A demographic profile of survivors of intimate partner violence with disabilities. Journal of Interpersonal Violence, 29(17), 31673179. doi: https://doi.org/10.1177/0886260514534776

Ballan, M. S., Burke Freyer, M., \& Powledge, L. (2015). Intimate partner violence among men with disabilities: The role of health care providers. American Journal of Men's Health, 11(5), 1436-1443. Advance online publication. doi: https://doi.org/10.1177/1557988315606966

Ballan, M. S., Burke Freyer, M., Powledge, L., \& Marti, C. N. (2016). Intimate partner violence among help-seeking Deaf women: An empirical study. Violence Against Women. doi: https://doi.org/10.1177/1077801216664428

Barranti, C. C. R., \& Yuen, K.O. (2008). Intimate partner violence and women with disabilities: Toward bringing visibility to an unrecognized population. Journal of Social Work in Disability \& Rehabilitation, 7(2), 115-130. doi: https://doi.org/10.1080/15367100802081169

Breiding, M. J., \& Armour, B. S. (2015). The association between disability and intimate partner violence in the United States. Annals of Epidemiology, 25, 455-457. doi: https://doi.org/10.1016/j.annepidem.2015.03.017

Brownridge, D. A. (2006). Partner violence against women with disabilities: Prevalence, risk, and explanations. Violence Against Women, 12(9), 805-822. doi: https://doi.org/10.1177/1077801206292681

Chang, J. C., Martin, S. L., Moracco, K. E., Dulli, L., Scandlin, D., Loucks-Sorrel, M. B,...Bou-Saada, I. (2003). Helping women with disabilities and domestic violence: Strategies, limitations, and challenges of domestic violence programs and services. Journal of Women's Health, 12(7), 699-708. doi: https://doi.org/10.1089/154099903322404348

Copel, L. C. (2006). Partner abuse in physically disabled women: A proposed model for understanding intimate partner violence. Psychiatric Care, 42(2), 114-129. doi: https://doi.org/10.1111/j.1744-6163.2006.00059.x

Cramer, E. P, Gilson, S. F., \& DePoy, E. (2003). Women with disabilities and experiences of abuse. Journal of Human Behavior in the Social Environment, 7(3-4), 183-199. doi: https://doi.org/10.1300/J137v07n03 11

Curry, M. A., Renker, P., Hughes, R. B., Robinson-Whelen, S., Oschwald, M., Swank, P. R., \& Powers, L. E. (2009). Development of measures of abuse among women with disabilities and the characteristics of their perpetrators. Violence Against Women, 15(9), 1001-1025. doi: https://doi.org/10.1177/1077801209340306

Developmental Disabilities Assistance and Bill of Rights Act of 2000, P.L. 106-402 (2000).

Devries, K. M., Mak, J. Y., Bacchus, L. J., Child, J. C., Falder, G., Petzold, M., ... Watts, C. H. (2013). Intimate partner violence and incident depressive symptoms and 
suicide attempts: A systematic review of longitudinal studies. PLoS Med, 10(5), e1001439. doi: https://doi.org/10.1371/journal.pmed.1001439

Dillon, G., Hussain, R., Loxton, D., \& Rahman, S. (2013). Mental and physical health and intimate partner violence against women: A review of the literature. International Journal of Family Medicine, 2013, 1-15. doi: https://doi.org/10.1155/2013/313909

Douglas, E. M., \& Hines, D. A. (2011). The helpseeking experiences of men who sustain intimate partner violence: An overlooked population. Journal of Family Violence, 26(6), 473-485.

Elliott, D. E., Bjelajac, P., Fallot, R. D., Markoff, L. S., \& Reed, B. G. (2005). Traumainformed or trauma-denied: Principles and implementation of trauma-informed services for women. Journal of Community Psychology, 33(4), 461-477. doi: https://doi.org/10.1002/jcop.20063

Fallot, R., \& Harris, M. (2009). Creating cultures of trauma-informed care (CCTIC): A self-assessment and planning protocol. University of Iowa: Community Connections. Retrieved from: https://www.healthcare.uiowa.edu/icmh/documents/CCTICSelfAssessmentandPlanningProtocol0709.pdf

Frantz, B. L., Carey, A. C., \& Nelson-Bryen, D. (2006). Accessibility of Pennsylvania's victim assistance programs. Journal of Disability Policy Studies, 16, 209-219. doi: https://doi.org/10.1177/10442073060160040201

Garland-Thomson, R. (2002). Integrating disability, transforming feminist theory. NWSA Journal, 14(3), 1-32. doi: https://doi.org/10.2979/NWS.2002.14.3.1

Ghandour, R. M., Campbell, J. C., \& Lloyd, J. (2015). Screening and counseling for intimate partner violence: A vision for the future. Journal of Women's Health, 24(1), 57-61. doi: https://doi.org/10.1089/jwh.2014.4885

Hahn, J. W., McCormick, M. C., Silverman, J. G., Robinson, E. B., \& Koenen, K. C. (2014). Examining the impact of disability status on intimate partner violence victimization in a population sample. Journal of Interpersonal Violence, 29(17), 3063-3085. doi: https://doi.org/10.1177/0886260514534527

Harrell, E. (2015). Crimes Against Persons with Disabilities, 2009-2013 - Statistical Tables. Washington, D.C.: U.S. Department of Justice, Bureau of Justice Statistics.

Harris, M., \& Fallot, R. D. (2001). Envisioning a trauma-informed service system: A vital paradigm shift using trauma theory to design service systems. New Directions for Mental Health Services, 89, 11-12.

Hassouneh-Philips, D., \& McNeff, E. (2005). 'I thought I was less worthy': Low sexual and body esteem and increased vulnerability to intimate partner abuse in women with physical disabilities. Sexuality and Disability, 23(4), 227-240. doi: https://doi.org/10.1007/s11195-005-8930-3 
Hassouneh-Philips, D., McNeff, E., Powers, L., \& Curry, M. A. (2005). Invalidation: A central process underlying maltreatment of women with disabilities. Women and Health, 41(1), 33-50. doi: https://doi.org/10.1300/J013v41n01_03

Hoog, C. (2004). Model protocol on safety planning for domestic violence victims with disabilities. Seattle, WA: Abused Deaf Women's Advocacy Services for the Washington State Coalition Against Domestic Violence.

Hughes, R. B., Lund, E. M., Gabrielli, J., Powers, L. E., \& Curry, M. A. (2011). Prevalence of interpersonal violence against community-living adults with disabilities: A literature review. Rehabilitation Psychology, 56(4), 302-319. doi: https://doi.org/10.1037/a0025620

Khalifeh, H., Oram, S., Trevillion, K., Johnson, M., \& Howard, L.M. (2015). Recent intimate partner violence among people with chronic mental illness: Findings from a national cross-sectional survey. British Journal of Psychiatry, 207(3), 207-212. doi: 10.1192/bjp.bp.114.144899.

Lund, E. M. (2011). Community-based services and interventions for adults with disabilities who have experienced interpersonal violence: A review of the literature. Trauma, Violence, \& Abuse, 12(4), 171-182. doi: https://doi.org/10.1177/1524838011416377

Martin, S. L., Ray, N., Sotres-Alvarez, D., Kupper, L. L., Moracco, K. E., Dickens, P. A., ...Gizlice, Z. (2006). Physical and sexual assault of women with disabilities. Violence Against Women, 12(9), 823-837. doi: https://doi.org/10.1177/1077801206292672

Mays, J. M. (2006). Feminist disability theory: Domestic violence against women with disability. Disability \& Society, 21(2), 147-158. doi: https://doi.org/10.1080/09687590500498077

Mikton, C., Maguire, H., \& Shakespeare, T. (2014). A systematic review of the effectiveness of interventions to prevent and respond to violence against persons with disabilities. Journal of Interpersonal Violence, 29(17), 3207-3226. doi: https://doi.org/10.1177/0886260514534530

National Network to End Domestic Violence. (2016). Domestic violence counts 2015: A 24-hour census of domestic violence shelters and services. Washington, D.C.: Author.

Nosek, M. A., Howland, C., Rintala, D. H., Young, M. E., \& Chanpong, G. F. (2001). National study of women with physical disabilities: Final report. Sexuality and Disability, 19(1), 5-39. doi: https://doi.org/10.1023/A:1010716820677

Ortoleva, S., \& Lewis, H. (2012). Forgotten sisters - a report on violence against women with disabilities: An overview of its nature, scope, causes, and consequences. (Northeastern Public Law and Theory Faculty Research Papers Series No. 104-2012). Retrieved from http://womenenabled.org/pdfs/Ortoleva\%20Stephanie\%20\%20Lewis\%20Hope\%20et 
\%20al\%20Forgotten\%20Sisters\%20-

\%20A\%20Report\%20on\%20ViolenceAgainst\%20Women\%20\%20Girls\%20with\%2

0Disabilities\%20August\%2020\%202012.pdf

Plummer, S. B., \& Findley, P. A. (2012). Women with disabilities' experience with physical and sexual abuse: Review of the literature and implications for the field. Trauma, Violence, \& Abuse, 13(1), 15-29. doi: https://doi.org/10.1177/1524838011426014

Quiros, L., \& Berger, R. (2015). Responding to the sociopolitical complexity of trauma: An integration of theory and practice. Journal of Loss and Trauma, 20(2), 149-159. doi: https://doi.org/10.1080/15325024.2013.836353

Shakespeare, T. (2014). Disability rights and wrongs revisited (2nd ed.). New York: Routledge.

Strauser, D. R., Lustig, D. C., \& Uruk, A. C. (2007). Differences in self-reported trauma symptomatology between individuals with and without disability: An exploratory analysis. Rehabilitation Counseling Bulletin, 50(4), 216-225. doi: https://doi.org/10.1177/00343552070500040301

Substance Abuse and Mental Health Services Administration [SAMHSA]. (2015). Trauma-informed approach and trauma-specific interventions. Retrieved from http://www.samhsa.gov/nctic/trauma-interventions

Taft, C. T., Murphy, C. M., \& Creech, S. K. (2016). Introduction. In C. T. Taft, C. M. Murphy \& S. K. Creech (Eds.), Trauma-informed treatment and prevention of intimate partner violence (pp. 3-12). Washington, D.C.: American Psychological Association. doi: https://doi.org/10.1037/14918-001

Weissbecker, I., \& Clark, C. (2007). The impact of violence and abuse on women's physical health: Can trauma-informed treatment make a difference? Journal of Community Psychology, 35(7), 909-923. doi: https://doi.org/10.1002/jcop.20189

World Health Organization. (2011). World report on disability. Malta: Author. Retrieved from http://www.who.int/disabilities/world_report/2011/report/en/

Author notes: Address correspondence to: Michelle S. Ballan, Stony Brook School of Social Welfare, Health Sciences Center, 101 Nicolls Road, Stony Brook, NY 11794, 631304-5953, michelle.ballan@stonybrook.edu 